\begin{tabular}{lllll}
\hline Motrivivência & Ano XX, & No 30, P. 217-230 & Jun./2008 \\
\hline
\end{tabular}

\title{
A Regulamentação do Profissional de Educação Física: um diálogo com Herbert Marcuse
}

\section{The Professional's Of Physical Education Regulation: one dialogues with Herbert Marcuse}

\author{
Nicole Roessle Guiata? \\ Marcelo Moraes e Silva²
}

\begin{abstract}
Resumo
O presente ensaio busca efetuar uma análise crítica do processo de Regulamentação do Profissional de Educação Física, utilizando para isso os pensamentos do filósofo alemão

Herbert Marcuse. Concluímos através do diálogo com os escritos marcuseanos que o sistema CONFEF/ CREF é uma forma de adaptação a toda

a racionalidade irracional presente na sociedade capitalista, e que existe ainda espaço para uma utopia baseada nos princípios de uma sociedade verdadeiramente livre e emancipada.

Palavras Chaves: Educação Física; Regulamentação da Profissão; Herbert
Abstract
The present rehearsal search to make a critical analysis of the process of Regulation of the Professional of Physical education using for that the German philosopher's Herbert Mar- dialogue with the writings marcusea- nos that the system CONFEF / CREF is adaptations form the all the present irrational rationality in the capitalist society, and that still exists space for a Utopia based in the beginnings of a society truly free and emancipated.
Keywords: Physical education; Regulation of the Profession; Herbert Marcuse; cuse thoughts. Concluded through the

Marcuse.
\end{abstract}

1 Mestre em Educação - UFPR. Contato: nicoleguaita@yahoo.com.br

2 Mestre em Educação UFPR. Doutorando em Educação UNICAMP. Contato: moraes_marc@ yahoo.com.br 


\section{Considerações iniciais}

... quando falo de eliminação dos horrores da industrialização capitalista, não pretendo quebrar lanças em favor de uma romântica regressão aquém da técnica; pelo contrário, acredito que os benefícios da técnica e da industrialização só podem se tornar evidentes e reais quando forem removidas a industrialização e a técnica de tipo capitalista. (MARCUSE, 1969, p. 20-21).

O presente estudo tem como finalidade analisar o processo de regulamentação do profissional de Educação Física, tendo como referencial o legado deixado pelo filósofo alemão Herbert Marcuse.

Quem foi Herbert Marcuse? Segundo Dória (1983, p.13), Marcuse foi um filósofo alemão de origem judia, nascido em Berlim em agosto de 1898. Wiggershaus (2002) aponta que Marcuse desde muito cedo se tornou um observador crítico do marxismo que se consumia num dogmatismo por si mesmo produzido. Wiggershaus lembra também que Marcuse começou, em Berlim e Freiburg, a estudar história da literatura alemã como disciplina principal e filosofia e economia política como disciplinas complementares. De acordo com Jansen (1997, p.28), quase não existem documentos da primeira estada de Marcuse em Freiburg. Para Jansen o que se pode concluir deste período é que Marcuse já assistia às aulas de Martin Heidegger. Entretanto, Marcuse acabou tendo uma relação conturbada e polêmica com seu antigo professor. Primeiramente pela odisséia para a habilitação de sua tese na qual Heidegger não a aprovou. E num segundo momento pelo apoio de Heidegger ao nacional-socialismo alemão ${ }^{3}$.

Foi nesse tumultuado processo de habilitação de tese que Marcuse teve o primeiro contato com seus futuros companheiros do Instituto de Pesquisa Social, núcleo básico da Escola de Frankfurt, também denominada de Teoria Crítica da Sociedade, Max Horkheimer e Theodor W. Adorno ${ }^{4}$.Com a ascensão do nacional-socialismo na Alemanha os membros do Instituto são obrigados a fugir em 1933 para

3 Mais detalhes sobre esta questão consultar os textos três e quatro do livro organizado por Loureiro (1999).

4 Os detalhes sobre a difícil entrada de Marcuse no Instituto de Pesquisas Sociais (principalmente pelo apoio do membro Leo Löwental) são analisados com detalhes no livro de Loureiro (1999) e Wiggerhaus (2002). Segundo estes autores a dificuldade para a sua inserção era o fato de ser um ex-aluno de Martin Heidegger. 
Genebra e em 1934 o Instituto se instala nos Estados Unidos, país onde Marcuse irá exercer a docência universitária o restante de sua vida.

Herbert Marcuse ganhou um grande destaque no cenário mundial após o episódio de maio de 1968, pois ele declarou ser simpatizante da causa dos estudantes revolucionários europeus que desejavam reformular as estruturas de suas universidades ${ }^{5}$. Essa tomada de posição rendeu uma discordância com Theodor W. Adorno, que se posicionou contra os estudantes rebeldes em Frankfurt, inclusive mandando a polícia retirá-los do Instituto ${ }^{6}$. Entende-se que sua principal discordância com Adorno era na compreensão diversa que eles possuíam entre a relação teoria e prática.

De acordo com Pagni (2003, p.79), entre os teóricos de Frankfurt, Marcuse foi o que por mais tempo se manteve fiel às posições clássicas da primeira fase da Teoria Crítica ${ }^{7}$. Para Pagni a passagem para a segunda fase da Teoria
Crítica acontece principalmente com a publicação em 1966 do livro "Ideologia da Sociedade Industrial: O homem unidimensional". Horkheimer (1976, p.58-59), afirma que na primeira Teoria Crítica havia duas idéias básicas. A primeira era a de que a sociedade havia se tornada mais injusta pelo advento do nazifacismo, aumentando o sofrimento e impedindo as pessoas de pensar. E a solução para estes problemas seria a revolução. A outra idéia principal era que a sociedade só seria melhorada através de pensamentos verdadeiros, autênticos e que levem a um exercício pleno da liberdade ${ }^{8}$. Entretanto, Horkheimer lembra que a primeira fase da Teoria Crítica havia se mostrado falsa, pois muitos trabalhadores elevaram sua vida material, deixando de ser simples operários manuais. A sociedade havia caminhado para um mundo administrado até os últimos detaIhes, lócus no qual tudo passava a ser regulado pelo mercado. Nesse sentido, Pagni (2003, p.117), afirma que a segunda fase da Teoria Crítica

5 Foi na década de 70 que Herbert Marcuse alcançou reputação internacional sendo considerado uma das grandes vertentes do pensamento marxista. Foi neste momento que surgiu o termo três M referindo-se a Marx, Mao Tse Tung e o próprio Marcuse.

6 Mais detalhes sobre essa discordância conferir as cartas trocadas entre Marcuse e Adorno ver Loureiro (1999 p.87-107).

7 Segundo Pagni (2003, p.80), não são apenas as singularidades encontradas na obra de Marcuse que os distinguem dos outros frankfurtianos, pois o seu engajamento político era maior que dos demais membros.

8 Estas duas idéias, segundo Horkheimer (1976), ainda estava muito influenciada pelo pensamento de Marx. 
passa a não defender a revolução como alternativa, pois devido ao nazismo e ao stalinismo essa estratégia se converteu num novo tipo de terrorismo.

Desta forma, acredita-se que a segunda fase de Marcuse é a mais fecunda e será a mais explorada no presente ensaio, pois foi neste momento que o filosofo atingiu com muitas críticas o centro da ideologia capitalista industrial contemporânea, analisando com propriedade as revoluções tecnológicas e a sua racionalidade que esmagam os aspectos criadores da natureza humana.

Feita essas breves considerações pretende-se efetuar um diálogo entre algumas de suas obras com o processo de regulamentação da profissão de Educação Física. Apesar de Marcuse não ter vivido nesse período acredita-se que ele possa contribuir na análise de algumas questões relacionadas a presente temática.

\section{O diálogo}

Atualmente o sistema CONFEF/CREF, aponta-se como a grande solução e salvação para os problemas de desemprego estrutural e como a principal forma de "preservar" os professores de Educação Física das mazelas sociais em que vive a atual sociedade brasileira. Os seus defensores colocam a regulamentação da profissão como única forma "racional" da Educação Física e seus profissionais se autoconservarem na atual fase da social.

Os escritos de Barros (2000 p.108), um ferrenho defensor do sistema CONFEF/CREF indicam esta questão: "A regulamentação da profissão de Educação Física está sendo comemorada por aqueles que atuam nesse campo. Essa regulamentação é decorrência do desenvolvimento da área e das transformações sociais e econômicas ocorridas no país nos últimos anos".

Este sistema utiliza-se de um discurso de proteção da sociedade que na verdade tem como pano de fundo, apenas a defesa de seus interesses individuais. Sobre esse tipo de anseios, Marcuse (1982, p. 13), argumenta que: "As necessidades políticas da sociedade se tornam necessidades e aspirações individuais, sua satisfação promove os negócios e a comunidade, e o conjunto parece constituir a própria personificação da Razão". Ao articular os textos de Barros com o pensamento de Marcuse chega-se à conclusão que a regulamentação do profissional de Educação Física possui como objetivo principal atender as necessidades de uma pequena parte da sociedade.

Ao argumentar sobre a razão capitalista Marcuse (1981b, 
p.60), afirma que o setor da natureza controlado pelo homem por meio de métodos racionais foi racionalizado até os últimos detalhes em todas as esferas sociais, mas que permaneceu irracional como um todo. Este sistema que se diz racional como todo o restante da sociedade capitalista, trata-se na verdade de uma forma de adaptação irracional a toda uma sociedade irracional, onde a produtividade capitalista é destruidora do livre desenvolvimento das necessidades e faculdades humanas.

Marcuse (1981a, p.122), indica que no modelo de sociedade capitalista a racionalização é colocada como uma ordem divina e natural, mantida fora de uma compreensão crítica por mecanismos como os da psicologia, da religião, do patriotismo, da tradição, do preconceito, e principalmente pela Indústria Cultural que cada vez mais invade nossas casas sem pedir licença. Curiosamente este último mecanismo citado tem sido muito utilizado pelo sistema CONFEF/ CREF nos seus mais variados meios, mas gostar-se-ia de chamar a atenção para um lembrete publicitário estampado nas páginas de uma revista de grande circulação nacional. Nesta publicação é mostrado um boneco, vestindo trajes esportivos, sendo manipulado através de fios por uma mão. A mensagem que a propaganda vincula é a de alertar os leitores para o fato de não colocarem sua saúde, sua atividade física na mão de qualquer um. Mas aqui pergunta-se, quem manipula quem?

Entende-se que o sistema CONFEF/CREF possui o intuito de manter os seres humanos longe de uma crítica a toda essa racionalização, utilizando para isso um discurso baseado principalmente no preconceito $^{9}$ e na perseguição contra os denominados "leigos" que em muitos casos são profissionais de outras áreas do conhecimento ${ }^{10}$.

Estes pontos exemplificam que não é pelo fato de grande parte da comunidade da Educação Física filiar-se a esse sistema que ele se torna menos irracional e menos repreensível. E como argumenta Marcuse (1982 p. 17):
A distinção entre consciência verdadeira e falsa, entre inte- resse real e imediato, ainda tem significado. Mas a própria dis- tinção tem de ser validada. $\mathrm{O}$

9 Mais detalhes sobre a questão do preconceito ver as reflexões realizadas por Adorno e Horkheimer (1985), na Dialética do Esclarecimento, no capítulo onde os autores versam sobre a questão do anti-semitismo. Sobre a temática do preconceito indica-se o livro de autoria de Crochik (1995).

10 Os profissionais de outras áreas do conhecimento são os da dança, yoga, artes marciais, recreacionistas, fisioterapeutas e muitos outros. 
homem tem de vê-la e passar da consciência falsa para a verdadeira, do interesse imediato para o interesse real. Só poderá fazê-lo se viver com a necessidade de modificar o seu estilo de vida, de negar o positivo, de recusar. É precisamente essa necessidade que a sociedade estabelecida consegue reprimir com a intensidade com que é capaz de entregar as mercadorias em escala cada vez maior, usando a conquista científica da natureza para conquistar o homem cientificamente.

A aceitação da regulamentação por muitos profissionais ocorre, não por esse processo ser considerado benéfico e sim pelo enfraquecimento do ego e a sensação de desamparo causada pela sociedade administrada, o que faz surgir a "falsa necessidade ${ }^{11 "}$ de integrar-se a uma coletividade supostamente protetora, mas que nada mais é do que um conformismo a barbárie estabelecida na sociedade.

O pensamento de Marcuse pode indicar um entendimento desta conformação utilizada "por todos os conselhos profissionais", como uma forma de desviar o que deveria ser o verdadeiro interesse de um grupo social organizado: a libertação das garras do mundo das mercadorias e da exploração humana. Nessa busca não se deve pensar a Educação Física somente como uma mera aplicação de técnicas em movimentos humanos, limitando dessa forma sua análise na esfera cultural. Posição bem parecida com a defendida pelo sistema CONFEF/ CREF. Veja como esse organismo define atividade física e sua intervenção na sociedade:

\begin{abstract}
Atividade Física é todo movimento corporal voluntário que resulta num gasto energético acima dos níveis de repouso, caracterizado pela atividade do cotidiano e pelos exercícios físicos. Trata-se de comportamento inerente ao ser humano com características biológicas e sócio-culturais. No âmbito da Intervenção Profissional de Educação Física, a atividade física compreende a totalidade de movimentos corporais, executando no contexto de diversas práticas: ginásticas, exercícios físicos, desportos, jogos ... (CONFEF/CREF, 2002, RESOLUÇÂO n. $\left.{ }^{\circ} 46\right)$.
\end{abstract}

Esta redução das práticas corporais empobrece e negligencia a transmissão de elementos impor-

11 Essa conceituação marcuseana irá ser melhor trabalhada nas páginas a seguir. 
tantes da cultura, tornando essa prática social acéfala e reducionista, estando ela somente ligadas a preceitos utilitaristas. Barros (2000, p.108), ao defender a importância da regulamentação da profissão faz uma exaltação ao que Marcuse criticava no final dos anos 60:

O futuro da profissão em Educação Física, além da regulamentação, depende da competência técnico-científica e qualidade ética de seus profissionais. Um profissional competente que assuma um compromisso altruísta com a profissão e com a sociedade, de prestar o melhor serviço a um número cada vez maior de pessoas, retrata o perfil desejado.

Este positivismo científico e exaltação da técnica reinante nas obras, estatutos, códigos e normas ligados a este conselho são na verdade um reducionismo na forma de se pensar a Educação Física. Trata-se de um discurso de proteção da sociedade (interesse público) com a junção do interesse privado (empregabilidade dos professores) que na verdade têm como objetivo garantir o emprego dos professores de Educação Física, mas que na verdade ajuda manter o status quo da sociedade capitalista.

Marcuse (1982, p.18), comenta alguns pontos interessantes:
Nessa sociedade, o aparato produtivo tende a tornar totalitário no quanto determina não apenas as oscilações, habilidades e atitudes socialmente necessárias, mas também as necessidades e aspirações individuais. Oblitera, assim, a oposição entre existência privada e pública, entre necessidades individuais e sociais. A tecnologia serve para instruir formas novas, mais eficazes e mais agradáveis de controle e coesão social.

Esta suposta noção de "neutralidade" da tecnologia e da técnica não pode mais ser sustentada. Entende-se que a forma social baseada nestes valores trata-se de um sistema de dominação operante no conceito e elaboração das técnicas que escondem a defesa do interesses dominantes que objetivam efetuar uma coerção social. O novo ordenamento capitalista defende a implementação do paradigma toyotista, baseado nos princípios da Qualidade Total e da defesa da técnica associada à incorporação de novos valores como flexibilidade, trabalho em equipe e criatividade. Também exigem a formação de um trabalhador critico e criativo dentro do processo de produção, porém nunca além dele. Em consonância com este processo de reestruturação produtiva o processo de regulamentação incentiva o pro- 
fissional de Educação Física a adquirir estas características. Além disso, o sistema CONFEF/CREF de maneira alguma defende a regulamentação dos direitos trabalhistas, sendo um grande incentivador da desregulamentação das condições de trabalho tão em voga no atual modelo neoliberal. (SILVA; LANDIN, 2002).

\section{O sistema CONFEF/CREF}

no intuito de conformar-se às novas exigências tecnológicas vale-se de um expediente autoritário baseado na subordinação dos profissionais da área, utilizando principalmente o discurso de proteção da sociedade e de garantia de emprego. Trata-se de um mecanismo de falsa projeção dos profissionais em Educação Física em relação aos "leigos". Estas questões exigem um entendimento adequado sobre um sistema de dominação autoritário:

Todo esse sistema de subordinação à autoridade e aos ofícios, diga-se de passagem, deve ser fundamentado por meio do recurso à ordem divina: ele é estabelecido para castigar os maus, defender os bons e assegurar a paz, mas essa fundamentação não chega para sancionar exatamente aquele sistema de autoridade que existe, exatamente aqueles ofícios e autoridades particulares, assim como a maneira como utilizam a espada. (MARCUSE 1981a, p. 64).
Conforme já foi salientado, compreende-se que esse sistema surge como forma de adaptação ao novo momento capitalista. Essa intenção de conformação social pode ser visualizada na seguinte afirmação do presidente do sistema CONFEF/CREF, o professor Jorge Steinhilber (1998 p. 12):

Hoje retrógrado é quem está atrelado, ainda as antigas dicotomias esquerda-direita, progressistas-conservador. Para os dias atuais, mormente na área de educação física, importa não mais rótulos ideológicos, mas sim contemporaneamente a abertura dos horizontes e afinar-se com as novas realidades que emergem.

Esta passagem do presidente do sistema comprova a intenção de conformação desejada. Uma adaptação a toda ética de livre mercado. Nesta temática de nãoconformismo ao sistema e a sua liberdade econômica Marcuse (1982, p.24), possui uma crítica feroz:

Nas condições de um padrão de vida crescente, o não-conformismo com o próprio sistema parece inútil, principalmente quando acarreta desvantagens econômicas e políticas tangíveis e ameaça o funcionamento suave do todo. Na verdade, 
parece não haver razão alguma, pelo menos no quanto estejam compreendidas as necessidades da vida para que a produção e distribuição de mercadorias e serviços se dêem por intermédio da concorrência competitiva das liberdades individuais.

A liberdade de empreendimento não foi de modo algum desde o início, uma vantagem Quanto a liberdade de trabalhar ou morrer à míngua, significou labuta, insegurança e temor para a grande maioria da população. Se o indivíduo não mais fosse compelido a se demonstrar no mercado como um sujeito econômico livre, o desaparecimento desse tipo de liberdade seria uma das maiores conquistas da civilização. [...] A própria estrutura da existência humana seria alterada; o indivíduo seria libertado da imposição pelo mundo do trabalho, de necessidades e possibilidades alheias a ele; ficaria livre para exercer autonomia sobre uma vida que seria sua. Se o aparato produtivo pudesse ser organizado e orientado para a satisfação das necessidades vitais, seu controle bem poderia ser centralizado; tal controle não impediria a autonomia individual, antes tornando-a possível.

Marcuse argumenta que a implementação de necessidades materiais e intelectuais interfere diretamente na questão da liberdade humana. Baseados nessas questões acredita-se que os defensores da regulamentação utilizam deste dispositivo de coerção ao colocarem como necessidade de sobrevivência aos professores de Educação Física o fortalecimento do conselho, sendo este uma forma de "salvação" da profissão na atual sociedade, criando na mentalidade do professores de Educação Física algumas falsas necessidades, que são:

... aquelas superimpostas ao indivíduo por interesses sociais particulares ao reprimi-lo: as necessidades que perturbam a labuta, a agressividade, a miséria e a injustiça. Sua satisfação pode ser assaz agradável ao indivíduo, mas a felicidade deste não é uma condição que tem de ser mantida e protegida caso sirva para coibir o desenvolvimento da aptidão (dele e de outros) para reconhecer a moléstia do todo e aproveitar as oportunidades de cura. Então, o resultado é euforia na infelicidade. A maioria das necessidades comuns descansar, distrairse, comportar-se e consumir de acordo com os anúncios, amar e odiar o que os outros amam e odeiam, pertencem a essa categoria de falsas necessidades. (MARCUSE 1982, p. 26). 
Ao basear-se nos pensamentos acima apresentados indicase como hipótese que o processo de regulamentação tem como principal objetivo à tentativa de reserva de mercado, mas que no fundo acaba por garantir a dependência das "falsas necessidades" exigidas pelo capitalismo. Entretanto, conforme já foi salientado, para alcançar seu intuito elegem como inimigo central os denominados "leigos". Esse ódio e preconceito aos leigos podem ser comprovados em outro texto de Steinhilber (1996 p. 48-57):

Normalmente me indagam por que os leigos podem atuar no nosso mercado de trabalho [...] que este mercado pertence a qualquer um. Qualquer pessoa, com qualquer formação e, mesmo sem nenhuma formação pode atuar em academias, clubes, condomínios. [...] O que estou alertando é que estarão competindo com igualdades de condições com os leigos, expraticantes, curiosos e tantos outros que se arvoram e atuam na área de atividade física. [...] Estamos permitindo a extinção da E.F curricular. Estamos permitindo a extinção do Professor de E.F. Precisamos ter coragem de reverter este quadro, ocupar os espaços legítima e legalmente. [...] Muito me preocupa a frase que a licenciada de E.F. da Faculdade Maria Teresa escreveu: ser formado em E.F, é ver um leigo fazer aquilo que você levou 4 anos para aprender.

A utilização de mecanismos repressivos como o de ataque a outros indivíduos mostra como esse organismo visa manter a miséria dentro da organização cultural. Ações como estas não passam de uma tática totalitária e que incentiva a amplificação da barbárie na sociedade. É interessante salientar que estas ações preconceituosas são sempre justificadas pela ciência, que "teoricamente" o professor de Educação Física adquire na sua formação. Nesse sentido, o sistema CONFEF/CREF acredita que se deve eliminar os "leigos" do exercício profissional, visto que segundo os defensores do conselho os que não são formados num curso de Educação Física não possuem esse "conhecimento científico"12. Além disso, eles representam uma antiraça, uma ameaça que pode em muito prejudicar a sociedade. Desta forma, como afirma Crochik (1995),

12 É curioso destacar que o preconceito não é restrito a profissionais que não possuem um curso superior. Pode-se citar como exemplo a disputa de mercado travada entre os conselhos de Fisioterapia e de Educação Física. 
o preconceituoso é aquele que tem um ego frágil e persegue o "Outro" para esconder a sua própria fragilidade. Será que o profissional de Educação Física não é um fraco que quer mostrar sua força perseguindo os denominados "leigos"?

Marcuse (1982, p.26-27), argumenta que o prevalecimento das necessidades repressivas, como essas têm como prêmio toda a miséria de uma maioria pela satisfação de "falsas necessidades" de poucos. Para ele, as únicas necessidades que o indivíduo tem direito indiscutível são as necessidades vitais como alimentação, vestuário, moradia e acesso a um determinado nível cultural.

As questões sobre quais são as necessidades falsas e verdadeiras dos professores de Educação Física só podem ser respondido pelos próprios indivíduos e não por um determinado grupo de "iluminados" que têm apoio de uma parcela da comunidade da Educação Física ${ }^{13}$. Segundo Marcuse (1982, p. 27), a escolha sobre quais necessidades devem ser falsas ou verdadeiras devem ser feitas somente quando os indivíduos estiverem livres para dar sua resposta. Enquanto eles forem doutrinados e manipulados por uma coletividade a resposta que derem não podem ser tomada como sua.
A seguinte passagem de Marcuse (1969, p.19), mostra a relação entre repressão, coerção e necessidades vitais que na nossa opinião se encaixa perfeitamente na ótica de trabalho do sistema CONFEF/CREF:

Onde não existe a necessidade vital de eliminar o trabalho e, pelo contrário, existe a necessidade de conservá-lo, mesmo se não é mais socialmente necessário; onde não existe a necessidade vital do gozo, da alegria em boa consciência, mas antes a necessidade de ganhar o próprio sustento na mais miserável das vidas possíveis; em suma, onde essas necessidades vitais não surgem ou são sufocadas pelas repressivas, podemos esperar tão somente uma reconversão das novas potencialidades técnicas em potencialidades repressivas.

Isto também é valido para os movimentos contrários ao processo de regulamentação. Estes grupos de esquerda baseados num referencial materialista histórico dialético agem exatamente como o sistema CONFEF/CREF. A diferença está na articulação com um projeto histórico de sociedade. Quer-se deixar claro que se é contrário aos

13 Visto que existem muitos posicionamentos contrários ao sistema CONFEF/CREF. 
conselhos e concorda-se com vários pontos defendidos pelos movimentos críticos a esse sistema, contudo, discorda-se com a forma dogmática aplicada por esses grupos, que em muitos momentos não passa de um fascismo de esquerda.

Marcuse (1999, p.109), já chamava a atenção para esse perigo encontrado nas práticas política da esquerda:

Hoje vejo como um dos maiores, tanto da nova quanto da veIha esquerda, fazer novamente da teoria marxista um dogma, esquecendo que é uma teoria dialética, ou seja, esquecendo que é uma teoria histórica, que as mudanças históricas precisam entrar nos seus próprios conceitos fundamentais e que estes precisam continuar sendo capazes de captar a estrututra modificada do capitalismo.

E para realizar essa metamorfose a comunidade da Educação Física tem que pensar e refletir a função, tanto do processo da regulamentação como dos movimentos contrários a ele, pois as ações coletivas aniquilam o indivíduo e tendem ao fracasso, exemplo disso são as inúmeras revoluções realizadas por força da espada. Marcuse (1982, p. 28), comenta isso da seguinte maneira: "Toda libertação depende da consciência de servidão e o surgimento dessa consciência é sempre impedido pela predominância de necessidades e satisfações que se tornam, em grande proporção, do próprio indivíduo".

Qualquer semelhança com o sistema CONFEF/CREF será mera coincidência? Acredita-se que não seja, e sim, mais uma forma da intelectualidade adaptar a Educação Física a essa nova forma de organização cultural. Marcuse (1982, p. 31), coloca que a psicologia industrial há muito deixou de se limitar à fábrica. Sua forma de organização invadiu a sociedade como um todo, pois

... o domínio do capital, ampliado em todas as dimensões do trabalho e do lazer, controla a população subjacente, através dos bens e serviços que fornece e através da maquinaria política, militar e policial de assustadora eficiência.(MARCUSE, 1981b, p.16).

Embora os professores de Educação Física não atuem diretamente no processo industrial, essa prática social pode ser utilizada como importante meio de desenvolver valores, atitudes e comportamentos necessários ao desenvolvimento da lógica capitalista, pois ela trabalha diretamente nos processos de formação humana, 
seja nos processos de escolarização ou nos ambientes não-escolares.

\section{Consideraçôes finais}

Ações como as defendidas e apresentadas pelos defensores da regulamentação apontam que a única alternativa para a Educação Física brasileira seria o sistema CONFEF/CREF e, conseqüentemente, o de adaptação e conformação ao sistema capitalista.

Entretanto, Marcuse (1969, p.13), demonstra que existem alternativas:

Qualquer forma nova de vida sobre a terra, qualquer transformação do ambiente técnico e natural, é uma possibilidade real, que tem seu lugar próprio no mundo histórico. Podemos fazer do mundo um inferno, ou melhor, como vocês sabem, caminhamos para isso. Mas podemos fazer também o oposto.

E a possibilidade de fazer este oposto mostra que apesar de todas as impossibilidades colocadas pelo desenvolvimento tecnológico, ainda existe espaço para resistência e que de maneira alguma esse ideal tornou-se uma fantasia. (MARCUSE, 1969, p. 16).

Neste sentido, todas as lições dadas por esse instigante filó- sofo sobre a racionalidade irracional do capitalismo podem proporcionar uma reflexão sobre a sociedade administrada. Somente com uma postura de profunda reflexão sobre o sistema CONFEF/CREF é a forma que este organismo vê a sociedade e que se poderá alcançar uma prática mais comprometida com as verdadeiras necessidades humanas .

E com essa intenção de crítica ao racionalismo capitalista e todas as suas formas de coerção social é que o presente estudo esperou ter contribuir para o debate acadêmico da área.

\section{Referências}

ADORNO, Theodor W. e HORKHEIMER, Max. Dialética do esclarecimento. Rio de Janeiro, Zahar, 1985.

BARROS, José Maria de Camargo. Educação Física, Profissão Regulamentada. Revista Brasileira de Ciências do Esporte, v.21(2/3), jan. /maio, 2000, p. 108-109.

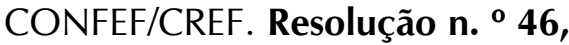
de 18 de fevereiro de 2002.

CROCHIK, José Leon. Preconceito: indivíduo e cultura. São Paulo, Robe Editorial, 1995.

DORIS, Francisco Antonio. Marcuse: Vida e Obra. $3^{\text {a }}$ ed. São Paulo, Paz e Terra, 1983. 
JANSEN, Peter-Erwin. O processo de habilitação de Marcuse - uma odisséia. In: LOUREIRO, Isabel. Herbert Marcuse: a grande recusa hoje. Petrópolis, Editora Vozes, 1999, p.27-40.

HORKHEIMER, Max. Sociedad em transición. Barcelona, Ediciones Península, 1976.

LOUREIRO, Isabel. Herbert

Marcuse: a grande recusa hoje. Petrópolis, Editora Vozes, 1999.

MARCUSE, Herbert. O Fim da Utopia. Rio de Janeiro, Paz e Terra, 1969.

Idéias sobre uma Teoria

Crítica da Sociedade. $2^{a}$ ed. Rio de Janeiro, Zahar Editores, 1981a.

. Contra-Revolução e Revolta.

$2^{a}$ ed. Rio de Janeiro, Zahar Editores, 1981b.

A Ideologia da sociedade Industrial: O Homem Unidimensional. $6^{\text {a }}$ ed. Rio de Janeiro, Zahar Editores, 1982. .Pela frente única das esquerdas. In: LOUREIRO, Isabel. Herbert Marcuse: a grande recusa hoje. Petrópolis, Editora Vozes, 1999, p.109-123.

PAGNI, Pedro Angelo. Subjetividade, corpo e educação na obra de
Herbert Marcuse. Perspectiva. Florianópolis, v. 21, n. 01, p.79119, jan./jun.2003.

SILVA, Marcelo Moraes e LANDIM, Renata Aparecida Alves. Os impactos da regulamentação da profissão de Educação Física na prática pedagógica. In: ALMEIDA, Renan. Os Bastidores da Regulamentação do Profissional de Educação Física. Vitória, CEFD/UFES, p. 49-72. 2002.

STEINHILBER, Jorge. Profissional de Educação Física... Existe? In: CICLO DE PALESTRAS CAEFALAF-UERJ, Rio de Janeiro, 1996. Anais... Rio de Janeiro: CAEFALF/ UERJ, p. 43-58, 1996.

- Pontos, contrapontos e questões pertinentes à Regulamentação do Profissional de Educação Física. Mimeo. 1998.

WIGGERSHAUS, Rolf. A Escola de Frankfurt. Rio de Janeiro, DIFEL, 2002.

Recebido: 30/agosto/2009

Aprovado: 29/outubro/2009 